\title{
Practice guideline update summary: Efficacy and tolerability of the new antiepileptic drugs II: Treatment-resistant epilepsy
}

\author{
Report of the Guideline Development, Dissemination, and Implementation Subcommittee of \\ the American Academy of Neurology and the American Epilepsy Society
}

Andres M. Kanner, MD, Eric Ashman, MD, David Gloss, MD, MPH\&TM, Cynthia Harden, MD, Blaise Bourgeois, MD, Jocelyn F. Bautista, MD, Bassel Abou-Khalil, MD, Evren Burakgazi-Dalkilic, MD, Esmeralda Llanas Park, MD, John Stern, MD, Deborah Hirtz, MD, Mark Nespeca, MD, Barry Gidal, PharmD, Edward Faught, MD, and Jacqueline French, MD

Neurology ${ }^{\circledR}$ 2018;91:82-90. doi:10.1212/WNL.0000000000005756

\section{Abstract}

\section{Objective}

To update the 2004 American Academy of Neurology guideline for managing treatmentresistant (TR) epilepsy with second- and third-generation antiepileptic drugs (AEDs).

\section{Methods}

2004 criteria were used to systemically review literature (January 2003 to November 2015), classify pertinent studies according to the therapeutic rating scheme, and link recommendations to evidence strength.

\section{Results}

Forty-two articles were included.

\section{Recommendations}

The following are established as effective to reduce seizure frequency (Level A): immediate-release pregabalin and perampanel for TR adult focal epilepsy (TRAFE); vigabatrin for TRAFE (not firstline treatment); rufinamide for Lennox-Gastaut syndrome (LGS) (add-on therapy). The following should be considered to decrease seizure frequency (Level B): lacosamide, eslicarbazepine, and extended-release topiramate for TRAFE (ezogabine production discontinued); immediate- and extended-release lamotrigine for generalized epilepsy with TR generalized tonic-clonic (GTC) seizures in adults; levetiracetam (add-on therapy) for TR childhood focal epilepsy (TRCFE) (1 month-16 years), TR GTC seizures, and TR juvenile myoclonic epilepsy; clobazam for LGS (add-on therapy); zonisamide for TRCFE (6-17 years); oxcarbazepine for TRCFE (1 month-4 years). The text presents Level $\mathrm{C}$ recommendations. AED selection depends on seizure/syndrome type, patient age, concomitant medications, and AED tolerability, safety, and efficacy. This evidencebased assessment informs AED prescription guidelines for TR epilepsy and indicates seizure types and syndromes needing more evidence. A recent Food and Drug Administration (FDA) strategy allows extrapolation of efficacy across populations; therefore, for focal epilepsy, eslicarbazepine and lacosamide (oral only for pediatric use) as add-on or monotherapy in persons $\geq 4$ years of age and perampanel as monotherapy received FDA approval.

\author{
Correspondence \\ American Academy of \\ Neurology \\ guidelines@aan.com
}

\section{RELATED ARTICLE}

Special Article

Practice guideline update summary: Efficacy and tolerability of the new antiepileptic drugs I:

Treatment of new-onset epilepsy: Report of the Guideline Development, Dissemination, and Implementation Subcommittee of the American Academy of Neurology and the American Epilepsy Society Page 74

From Miller School of Medicine (A.M.K.), University of Miami, FL; Bronson Methodist Hospital (E.A.), Kalamazoo, Ml; Charleston Area Medical Center (D.G.), Charleston, WV; Mount Sinai Beth Israel (C.H.), New York, NY; Children's Hospital, Harvard Medical School (B.B.), Boston, MA; Cleveland Clinic Foundation (I.F.B.), OH; Department of Neurology (B.-A.K.), School of Medicine, Nashville, TN; Cooper Medical School (E.B.-D.), Rowan University, Cherry Hill, NJ; Alexian Brothers Medical Group (E.L.P.), Hoffman Estates, IL; School of Medicine (J.S.), University of California in Los Angeles; University of Vermont Medical Center (D.H.), Burlington; Children's Hospital (M.N.), University of California San Diego School of Medicine; School of Pharmacy (B.G.), University of Wisconsin, Madison; Emory University School of Medicine (E.F.), Atlanta, GA; and New York University (J.F.), New York.

Go to Neurology.org/N for full disclosures. Funding information and disclosures deemed relevant by the authors, if any, are provided at the end of the article.

Approved by the Guideline Development, Dissemination, and Implementation Subcommittee on July 18, 2015; by the Practice Committee on December 2, 2015; by the American Epilepsy Society Board of Directors on January 16, 2018; and by the AAN Institute Board of Directors on April 18, 2018. 


\section{Glossary}

AAN = American Academy of Neurology; AE = adverse event; AED = antiepileptic drug; AES = American Epilepsy Society; CLB = clobazam; ESL = eslicarbazepine; EZG = ezogabine; FBM = felbamate; FDA = Food and Drug Administration; GBP = gabapentin; GE = generalized epilepsy; GTC = generalized tonic-clonic; JME = juvenile myoclonic epilepsy; LCM = lacosamide; LEV = levetiracetam; LEV-XR = extended-release levetiracetam; LTG = lamotrigine; LTG-XR = extended-release lamotrigine; OXC = oxcarbazepine; OXC-XR = extended-release oxcarbazepine; PER = perampanel; PGB = pregabalin; PGB$\mathbf{C R}=$ controlled-release pregabalin; PGB-IR = immediate-release pregabalin; $\mathbf{R F N}=$ rufinamide; $\mathbf{T G B}=$ tiagabine; $\mathbf{T P M}=$ topiramate; TPM-XR = extended-release topiramate; TR = treatment-resistant; TRAFE = treatment-resistant adult focal epilepsy; VGB = vigabatrin; ZNS = zonisamide.

In 2004, the American Academy of Neurology (AAN) and the American Epilepsy Society (AES) published a guideline on felbamate $(\mathrm{FBM})^{1}$ and another guideline on 8 secondgeneration antiepileptic drugs (AEDs) (table 1 shows principal findings). ${ }^{2}$ Since the 2004 publications, the US Food and Drug Administration (FDA) approved 6 new third-generation AEDs and 2 older AEDs (table 2). This update reviews new evidence for efficacy of these AEDs in managing treatment-resistant (TR) focal epilepsies and generalized epilepsies (GEs) in children and adults. The FDA also approved an additional new drug, brivaracetam, and an additional indication for perampanel (for primary generalized tonic-clonic [GTC] seizures) since the 2004 guideline that are not included in this update. These were excluded because they received FDA approval after the date of the last literature search update in November 2015; per the AAN guideline development process, studies not retrieved in a literature search cannot be included in the systematic review.

A companion guideline update examines the evidence in newonset focal epilepsy or GE.

This article summarizes the guideline findings, conclusions, and recommendations. The complete guideline, including appendices e- 1 through e-6, cited here, is available at links. lww.com/WNL/A563, and tables e-1 through e-6 at links. lww.com/WNL/A561.

\section{Description of the analytic process}

The AAN and AES convened an expert panel to develop this guideline using the 2004 AAN guideline development process. ${ }^{3}$ The complete guideline (data supplement at links.lww.com/WNL/A563) describes the literature search strategy and evidence review process. Class IV studies are not discussed.

\section{$\oplus$ Supplemental Data}

NPub.org/9j9777

\section{Analysis of evidence}

\section{For adult patients with TR focal epilepsy, are these AEDs effective as adjunctive therapy in reducing seizure frequency?}

\section{Pregabalin}

Pregabalin (PGB) was examined in 2 Class I and 2 Class II studies on immediate-release PGB (PGB-IR) ${ }^{4-7}$ and 1 Class I study of controlled-release PGB (PGB-CR). ${ }^{8}$

PGB was significantly superior to placebo at daily doses of 150,300 , and $600 \mathrm{mg}$, with $>50 \%$ responder rates and greater median percent seizure reduction, in a dose-related manner. Dizziness and sedation were the most frequently occurring adverse events (AEs) and AE-related drug discontinuation reported, which increased in frequency with higher doses.

A Class I study compared placebo with PGB-CR 165 and 330 $\mathrm{mg} / \mathrm{d}^{\mathrm{e}}{ }^{\mathrm{s}}$ The 3 arms failed to differ. AEs and AE-related discontinuation rates were higher in the high-dose arm and similar to the trials with PGB-IR. ${ }^{6-8}$

\section{Conclusions}

PGB-IR is effective as add-on therapy for TR adult focal epilepsy (TRAFE) (2 Class I studies). Efficacy and AEs increased with higher doses. PGB-CR is probably not effective (1 Class I study).

\section{Clinical context}

The initial PGB-IR doses were higher than typically used in clinical practice $(25-50 \mathrm{mg} / \mathrm{d}$ ) and may have led to higher AE occurrence rate. The lack of efficacy of PGB-CR compared with placebo may be due to an exceptionally high placebo responder rate or the failure to use maximal doses (e.g., $600 \mathrm{mg} / \mathrm{d}$ ).

\section{Lacosamide}

Lacosamide (LCM) and placebo were compared in 1 Class I and 2 Class II studies. ${ }^{9-11}$ LCM at doses of 400 and $600 \mathrm{mg} / \mathrm{d}$ showed significantly higher responder rates and greater median reduction of seizures than placebo. One Class II study $^{10}$ showed $600 \mathrm{mg} / \mathrm{d}$ yielded a greater reduction in secondarily GTC seizures. Dose-dependent discontinuation 
Table 1 Summary of first guidelines on the use of antiepileptic drugs (AEDs) in treatment-resistant epilepsy, based on Level $A$ and $B$ recommendations ${ }^{3}$

\begin{tabular}{|c|c|c|c|c|c|}
\hline AED & $\begin{array}{l}\text { Adjunctive } \\
\text { focal adult }\end{array}$ & $\begin{array}{l}\text { Focal } \\
\text { monotherapy }\end{array}$ & IGE & LGS & $\begin{array}{l}\text { Adjunctive } \\
\text { focal pediatric }\end{array}$ \\
\hline Gabapentin & Yes & No & No & No & Yes \\
\hline Lamotrigine & Yes & Yes & Yes (only in CAE) & Yes & Yes \\
\hline Levetiracetam & Yes & No & No & No & No \\
\hline Oxcarbazepine & Yes & Yes & No & No & Yes \\
\hline Tiagabine & Yes & No & No & No & No \\
\hline Topiramate & Yes & Yes & Yes & Yes & Yes \\
\hline Zonisamide & Yes & No & No & No & No \\
\hline
\end{tabular}

Abbreviations: CAE = childhood absence epilepsy; IGE = idiopathic generalized epilepsy; LGS = Lennox-Gastaut syndrome.

because of AEs was not universally observed. AEs were diplopia, vertigo, and emesis in the Class I study ${ }^{9}$ and dizziness, nausea, fatigue, ataxia, diplopia, and nystagmus in the Class II studies. ${ }^{10,11}$

A Class III study assessed the parenteral formulation of LCM. ${ }^{12}$ Headache, dizziness, and somnolence were the most common AEs, with increased frequency for doses $>400 \mathrm{mg} / \mathrm{d}$.

\section{Conclusion}

LCM is probably effective in TRAFE (1 Class I study).

\section{Clinical context}

Initial LCM doses were higher than typically used in clinical practice $(50-100 \mathrm{mg} / \mathrm{d})$ and may have led to a higher AE occurrence rate. Pooled data suggested dizziness was twice as frequent when LCM was used with other sodium channel drugs. ${ }^{13}$

Table 2 Mechanism of action of the 8 newly approved antiepileptic drugs (AEDs)

\begin{tabular}{|c|c|}
\hline AED & Mechanism of action \\
\hline Clobazam & $\begin{array}{l}\text { Binding to benzodiazepine at the } \mathrm{GABA}_{\mathrm{A}} \text { ligand-gated } \\
\text { chloride channel complex }\end{array}$ \\
\hline Eslicarbazepine & $\begin{array}{l}\text { Use-dependent blockage of voltage-sensitive sodium } \\
\text { channels }\end{array}$ \\
\hline Ezogabine & $\begin{array}{l}\text { Positive allosteric modulator of KCNQ2-5; positive } \\
\text { allosteric modulator of } \mathrm{GABA}_{\mathrm{A}} \text { receptors }\end{array}$ \\
\hline Lacosamide & $\begin{array}{l}\text { Slow inactivation of voltage-gated sodium channels; } \\
\text { binds to CRMP-2 }\end{array}$ \\
\hline Perampanel & AMPA receptor antagonist \\
\hline Pregabalin & $\begin{array}{l}\text { Binding to the a2- } \delta \text { protein subunit of voltage-gated } \\
\text { calcium channels }\end{array}$ \\
\hline Rufinamide & $\begin{array}{l}\text { Use-dependent blockage of voltage-sensitive sodium } \\
\text { channels }\end{array}$ \\
\hline Vigabatrin & Inactivation of GABA transaminase \\
\hline
\end{tabular}

\section{Rufinamide}

Rufinamide (RFN) and placebo were compared in 3 Class I studies. ${ }^{14-16}$ RFN was superior to placebo in reduction of median seizure frequency per 28 days and in $>50 \%$ responder rates; $400 \mathrm{mg} / \mathrm{d}$ was the lowest effective dose. Effects were consistently modest.

The most frequent AEs were dizziness, fatigue, nausea, somnolence, diplopia, confusion, ataxia, and impaired concentration.

\section{Conclusion}

RFN is effective as add-on therapy for LGS, but benefits are modest (3 Class I studies).

\section{Ezogabine}

Ezogabine (EZG) and placebo were compared in 3 Class II studies. ${ }^{17-19}$ EZG at 600,900 , or $1,200 \mathrm{mg} / \mathrm{d}$ was superior to placebo for median percent seizure reduction and responder rates.

Treatment-related AEs were dose-dependent and included dizziness, somnolence, headache, and fatigue. The most common AEs resulting in discontinuation were dizziness and somnolence. In a Class III study, ${ }^{20}$ a significantly higher $\mathrm{AE}$ rate occurred with titration rates of $<7$ days.

\section{Conclusions}

EZG is probably effective as add-on therapy for TRAFE (3 Class II studies).

\section{Clinical context}

In April 2013, the FDA issued a warning that EZG can cause blue skin discoloration and retina pigment changes, and recommended that any patient taking EZG have baseline and periodic eye examinations. Ezogabine production was discontinued in June 2017.

\section{Vigabatrin}

Vigabatrin (VGB) and placebo were assessed in 2 Class I studies. ${ }^{21,22}$ VGB doses at 1,3 , and $6 \mathrm{~g} / \mathrm{d}$ yielded significantly 
higher responder rates and median reduction in monthly seizure frequency. Fatigue and drowsiness were the most frequent AEs, with a higher drug discontinuation rate in the $6 \mathrm{mg} / \mathrm{d}$ group.

In 1997, 1 study found irreversible retinopathies resulting in bilateral concentric constriction of visual fields associated with higher cumulative doses and increasing age. ${ }^{23}$ The FDA requires patients to undergo visual field examinations every 3 months.

\section{Conclusion}

VGB is effective as add-on therapy in TRAFE (2 Class I studies).

\section{Clinical context}

Benefits of VGB should be weighed against the risks, particularly risk of irreversible retinopathy.

\section{Clobazam}

Clobazam (CLB) and placebo were assessed in 3 Class III studies, 2 of which had $<30$ participants, and the larger study included both focal epilepsy and GE. ${ }^{24-26}$ Doses in the larger trial ranged from $10-40 \mathrm{mg} / \mathrm{d}^{24}$ Patients randomized to CLB had significantly greater seizure frequency reduction and responder rates. AEs were more frequent with CLB and included sedation, dizziness, irritability, depression, and disinhibition.

\section{Conclusion}

CLB is possibly effective as add-on therapy for TRAFE (3 Class III studies). Generalizability may be limited (2 studies had small numbers; the larger study had possibly mixed groups of focal and generalized epilepsy types).

\section{Perampanel}

Perampanel (PER) was compared with placebo in 3 Class I studies. $^{27-29}$ Doses of 4,8 , and $12 \mathrm{mg} / \mathrm{d}$ were superior to placebo in median percent reduction in seizure frequency per 28 days. The dose response rate varied between the studies, perhaps because of a very high placebo rate.

The most common AEs included dizziness, ataxia, falls, headache, somnolence, fatigue, irritability, depression, nausea, and weight gain. AEs were dose-related and occurred during both titration and maintenance phases. Irritability and aggressive behavior prompted a package insert warning.

\section{Conclusion}

PER is established as effective as add-on therapy in TRAFE (3 Class I studies).

\section{Clinical context}

Patients should be monitored closely for the occurrence of psychiatric AEs, in particular irritability and aggressive behavior.

\section{Eslicarbazepine}

Eslicarbazepine (ESL) and placebo were compared in 3 studies ( 1 Class I, 1 Class II, 1 Class III). ${ }^{30-32}$ Single daily doses of 400, 800, and 1,200 mg were investigated. ESL at 800 $\mathrm{mg} / \mathrm{d}$ and $1,200 \mathrm{mg} / \mathrm{d}$ significantly reduced seizure frequency per 4-week period in all 3 studies and yielded significantly higher responder rates in the Class I and III studies. In the Class I study, the seizure-free rate was higher for the $1,200 \mathrm{mg}$ dose.

Treatment-related AEs were generally dose-dependent, including those leading to drug discontinuation. The most frequent AEs were dizziness, headache, diplopia, somnolence, nausea, emesis, and coordination difficulties.

\section{Conclusion}

ESL doses of 800 and 1,200 $\mathrm{mg} / \mathrm{d}$ are probably effective in TRAFE (1 Class I study).

\section{Clinical context}

The Class I study may have limited generalizability because $100 \%$ of patients were Caucasian. Tolerability may have been affected, as $>50 \%$ of patients were concurrently taking carbamazepine, which is chemically related to ESL.

\section{Extended-release oxcarbazepine}

One Class II study compared the extended-release formulation of oxcarbazepine (OXC-XR) with placebo. ${ }^{33}$ Significant differences between $\mathrm{OXC}$-XR and placebo were achieved with the $2,400 \mathrm{mg} / \mathrm{d}$ dose for responder rates and median percent seizure rate reduction. Placebo rates outside the United States were very high. When only the North American cohort was assessed, the $1,200 \mathrm{mg} / \mathrm{d}$ dose was superior to placebo. The most frequent AEs, including those leading to drug discontinuation, were dizziness, ataxic gait, nausea, vomiting, headache, somnolence, fatigue, and diplopia.

\section{Conclusion}

OXC-XR 2,400 mg/d is possibly effective for treating TRAFE (1 Class II study).

\section{Extended-release topiramate}

A Class I study investigated the extended-release formulation of topiramate (TPM-XR) at $200 \mathrm{mg} / \mathrm{d} .{ }^{34}$ It was superior to placebo for responder rates and median percent reduction in weekly focal seizure rates. Discontinuation because of AEs was more frequent in patients randomized to TPM-XR; the most frequent AEs were somnolence, paresthesia, and weight loss.

\section{Conclusion}

TPM-XR is probably effective as add-on therapy for TRAFE (1 Class I study).

\section{Recommendations}

For TRAFE, immediate-release PGB and PER are established as effective to reduce seizure frequency (Level A). LCM, ESL, and TPM-XR use should also be considered to decrease seizure frequency in this population (Level B). VGB and RFN 
should be considered established as effective for decreasing seizure frequency in TRAFE (Level A) but are not first-line agents (retinopathy risk with VGB and modest benefit with RFN). EZG use should be considered to decrease seizure frequency in this population (Level B) but carries a serious risk of skin and retinal discoloration. CLB and OXC-XR use may be considered to decrease seizure frequency in TRAFE (Level C).

\section{For adult patients with TR focal epilepsy, are these AEDs effective in reducing seizure frequency when used as monotherapy?}

In the 2004 guideline, lamotrigine (LTG), oxcarbazepine (OXC), and topiramate (TPM) were found to be effective in TRAFE. Since then, 5 Class III conversion-to-monotherapy studies have been conducted using historical controls. One study evaluated extended-release levetiracetam (LEV-XR), ${ }^{35}$ 1 evaluated $\mathrm{PGB},{ }^{36} 1$ evaluated $\mathrm{LCM}^{37}$ and 2 evaluated ESL. $^{38,39}$

In the LEV-XR study, 1,000 and 2,000 $\mathrm{mg} / \mathrm{d}$ doses were used. $^{35}$ In the PGB study, 150 and $600 \mathrm{mg} / \mathrm{d}$ doses were evaluated. ${ }^{36}$ For LCM, 300 and $400 \mathrm{mg} / \mathrm{d}$ doses were compared with historical controls. ${ }^{37}$ The ESL studies investigated 1,200 and $1,600 \mathrm{mg} / \mathrm{d}$ doses. ${ }^{38,39}$

In all 4 drugs, the predicted exit rate was significantly lower for patients randomized to the higher doses for LEV-XR and PGB and to both doses for LCM and ESL compared with the historical controls. The most frequent AEs associated with LEV-XR included somnolence, headaches, and convulsions and did not differ between the 2 doses. For PGB, the most frequent AEs were similar to those reported in the add-on PGB trials previously described. ${ }^{6-8}$ For LCM, the most common AEs were dizziness, headache, nausea, convulsions, somnolence, and fatigue, most of which were of mild to moderate severity and comparable between the 2 doses; dizziness occurred more in the 400-mg group. For ESL, the most frequent AEs included dizziness, headache, fatigue, somnolence, nausea, and nasopharyngitis and were dosedependent.

\section{Conclusions}

ESL is possibly effective as monotherapy for TRAFE (2 Class III studies). Evidence is insufficient to determine the efficacy of LCM, LEV-XR, or PGB as monotherapy for TRAFE (1 Class III study per drug). No new Class I, II, or III studies have been published on CLB, EZG, gabapentin (GBP), PER, RFN, tiagabine (TGB), VGB, or zonisamide (ZNS).

\section{Recommendations}

ESL use may be considered to decrease seizure frequency as monotherapy for TRAFE (Level C).

Data are insufficient to recommend the use of second- and the other third-generation AEDs as monotherapy in TRAFE (Level U).
For adult and pediatric patients with TR GE, are these AEDs effective in reducing seizure frequency when used as adjunctive therapy (compared with no adjunctive therapy)?

The 2004 guidelines found only TPM to be effective as addon therapy in TR GTC seizures in adults and children. Since then, $3 \mathrm{LTG}^{40, \mathrm{e} 1, \mathrm{e} 2}$ and 2 levetiracetam $(\mathrm{LEV})^{\mathrm{e} 3, \mathrm{e} 4}$ (links. lww.com/WNL/A562) studies have been published.

\section{Lamotrigine}

LTG to treat TR GTC at several doses (depending on age and type of additional AED used) were compared with placebo in 1 Class II study with patients aged 2-55 years. ${ }^{40}$ Twelve-week median percent reduction of GTC seizure frequency and responder rates were significantly higher for patients randomized to LTG. The most common LTG-related AEs included dizziness, somnolence, and nausea.

A second Class II study ${ }^{\mathrm{e}}$ demonstrated significant differences in median percent decrease from baseline in GTC seizures favoring LTG during both escalation and maintenance periods. AEs leading to drug discontinuation were rare. No rashes were reported.

Similar findings were obtained in a Class I study that included adolescents and adults using extended-release LTG (LTGXR). ${ }^{\text {2 }}$ Those on LTG-XR experienced a significantly greater median percent reduction in weekly GTC seizure frequency and had a higher responder rate. Nausea, vomiting, and diplopia were the most frequent AEs related to LTG-XR.

\section{Conclusion}

Both LTG-XR and immediate-release LTG are probably effective as add-on therapy for TR GTC seizures (1 Class I study for LTG-XR; 2 Class II studies for immediaterelease LTG).

\section{Levetiracetam}

Two Class I studies compared 3,000 mg/d LEV and placebo in TR GE. One study included patients aged 4-65 years. ${ }^{\text {e3 }}$ LEV demonstrated significantly greater responder rates and GTC-free frequency. The second study assessed adolescents and adults with juvenile myoclonic epilepsy (JME) or juvenile absence epilepsy. ${ }^{\text {e4 }}$ Compared with those on placebo, significantly more patients on $\mathrm{LEV}$ had a $>50 \%$ reduction in the number of days per week with myoclonic seizures, became free of myoclonic seizures, and became free of all seizure types. In the first study, more patients on placebo discontinued therapy because of AEs, but irritability, fatigue, somnolence, and headache occurred in patients on LEV. Somnolence and neck pain were the only 2 AEs seen with greater frequency among patients on LEV in the second study.

\section{Conclusions}

LEV is probably effective as add-on therapy for TR GE presenting with GTC seizures (1 Class I study). LEV is probably effective as add-on therapy for TR JME and juvenile absence 
seizures (1 Class I study). The data from these studies could be generalized to all patients with TR GE; however, the requirement of at least 3 GTC seizures during the 8-week baseline phase in the first study pertains to patients with more severe GE.

\section{Clinical context}

Only high LEV doses were used.

\section{Recommendations}

For add-on therapy for GE, immediate-release and LTG-XR use should be considered as add-on therapy to decrease seizure frequency in treating adults with TR GTC seizures secondary to GE (Level B). Levetiracetam use should be considered to decrease seizure frequency as add-on therapy for TR GTC seizures and for TR JME (Level B).

\section{Clinical context}

Because the seizures of most patients with idiopathic GE are easily controlled with appropriate medication, presentation of TR epilepsy is rare. It is unclear how results in this population would translate to patients with similar syndromes but with nonrefractory disease.

\section{For adult and pediatric patients with LGS, are these AEDs effective as adjunctive therapy in reducing seizure frequency (compared with no adjunctive therapy)?}

In the 2004 guidelines, FBM, LTG, and TPM were found to be effective in treating LGS. Since then, studies of CLB and RFN have been published.

\section{Clobazam}

CLB efficacy was compared with placebo in 2 Class II studies. Three daily doses $(0.25,0.5$, and $1 \mathrm{mg} / \mathrm{kg}$ ) were examined. $^{\text {e5,e6 }}$ Relative to baseline seizure frequency, weekly drop seizure rates were significantly reduced with all 3 doses, with greater reduction in the high-dose group. Nondrop seizures were also reduced in a dose-dependent manner. The most common AEs included somnolence, lethargy, sedation, salivary hypersecretion, constipation, aggression, hypomania, and insomnia. Lethargy, aggression, ataxia, fatigue, and aggression were the most frequent AEs leading to drug discontinuation.

\section{Conclusion}

CLB is probably effective as add-on therapy for LGS (2 Class II studies).

\section{Rufinamide}

Two Class I studies compared RFN with placebo in children and young adults. ${ }^{\text {7,e8 }}$ Doses up to $45 \mathrm{mg} / \mathrm{kg} / \mathrm{d}$ were examined. Patients randomized to RFN experienced significantly greater median percent reductions in total seizure frequency and frequency of drop attacks and greater median percent change in tonic-atonic seizures. Common AEs included somnolence, vomiting, and decreased appetite.

\section{Conclusion}

RFN is established as effective as add-on therapy for LGS (2 Class I studies).

\section{Recommendations}

For LGS, RUF use should be considered established as effective to decrease seizure frequency as add-on therapy (Level A), and CLB use should be considered (Level B).

\section{For pediatric patients with TR focal epilepsy, are these AEDs effective as adjunctive therapy in reducing seizure frequency (compared with no adjunctive therapy)?}

In the 2004 guideline, GBP, LTG, OXC, and TPM were found to be effective as add-on therapy in treating TR focal epilepsy in children. Since then, 4 studies have been published: 2 on LEV, 1 on OXC, and 1 on ZNS.

\section{Levetiracetam}

Two Class I studies compared LEV with placebo. ${ }^{\text {e9,e10 }}$ The first study ${ }^{\mathrm{e} 9}$ included children and young adolescents (aged 4-16 years) and a target dose of $60 \mathrm{mg} / \mathrm{kg} / \mathrm{d}$. LEV had significantly greater responder rates per week and median reductions in seizure frequency per week. LEV was associated with more frequent AEs, which included somnolence, accidental injury, vomiting, anorexia, rhinitis, hostility, increased cough, pharyngitis, and nervousness. However, AE-related withdrawal from the study was higher among children randomized to placebo.

The second Class I study randomized children aged 1 month to $<4$ years to placebo or LEV at a dose of $40 \mathrm{mg} / \mathrm{kg} / \mathrm{d}$ (if aged $<6$ months) or $50 \mathrm{mg} / \mathrm{kg} / \mathrm{d}$ (if aged $\geq 6$ months) ${ }^{\text {e10 }}$ Children randomized to LEV had a significantly greater responder rate in average daily seizure frequency and greater median percent reduction from baseline. The most frequently reported LEVrelated AEs included somnolence and irritability.

\section{Conclusions}

LEV is probably effective as add-on therapy for TR focal epilepsy in children and adolescents (1 Class I study). Moreover, LEV is probably effective as add-on therapy in TR focal epilepsy in infants and children aged $<4$ years (1 Class I study).

\section{Oxcarbazepine}

One Class I study of children aged 1 month to $<4$ years compared 2 doses of OXC $(10 \mathrm{mg} / \mathrm{kg} / \mathrm{d}$ and $60 \mathrm{mg} / \mathrm{kg} / \mathrm{d}){ }^{\text {e11 }}$ The primary outcome was absolute change in the frequency of focal seizures per 24 hours during 3 days of continuous treatment-phase video EEG compared with baseline seizure frequency. Children on the higher OXC dose experienced a significantly greater seizure frequency reduction and a greater median percent reduction in seizure frequency per 24 hours than those on the low dose. Children in the highdose group also experienced more frequent $\mathrm{AEs}$, including somnolence, ataxia, and vomiting. 


\section{Conclusion}

OXC is probably effective as add-on therapy in infants and young children with TR focal epilepsy (1 Class I study). Given the study's short duration, however, generalizability may be limited.

\section{Zonisamide}

One Class I study of children and adolescents aged 6-17 years compared $8 \mathrm{mg} / \mathrm{kg} / \mathrm{d}$ ZNS to placebo. $^{\text {e12 }}$ The 12 -week responder rate was significantly higher for the patients randomized to ZNS. The incidence of AEs did not differ between the 2 groups, although AEs leading to withdrawal occurred more often in the placebo group. The AEs reported with a higher frequency in the ZNS group included decreased appetite, decreased weight, somnolence, vomiting, and diarrhea.

\section{Conclusion}

ZNS is probably effective as add-on therapy for TR focal epilepsy in children and adolescents (1 Class I study). Data are unavailable on the efficacy of CLB, ESL, LCM, PER, PGB, RFN, TGB, or VGB as add-on therapy for this group.

\section{Recommendations}

For add-on therapy for TR focal epilepsy, LEV use should be considered to decrease seizure frequency (Level B for ages 1 month to 16 years), ZNS use should be considered to decrease seizure frequency (Level B for ages 6-17 years), and OXC use should be considered to decrease seizure frequency (Level B for ages 1 month to 4 years).

Data are unavailable on the efficacy of CLB, ESL, LCM, PER, PGB, RFN, TGB, or VGB as add-on therapy for the treatment of these children or adolescents (Level U).

\section{Clinical context}

A pharmacokinetic: pharmacodynamic analysis performed comparing adults with children receiving approved AEDs showed similar seizure reduction for the 2 groups when serum concentrations were similar. On the basis of these data, the FDA determined that efficacy of AEDs for focal seizures in adults can be extrapolated downward to children 4 years of age. $^{\text {e13,e14 }}$

\section{For pediatric patients with TR focal epilepsy, are these AEDs effective as monotherapy in reducing seizure frequency?}

No data are available to answer this question. Thus, no recommendation is made.

\section{Have new serious AEs been identified in the AEDs evaluated in the $\mathbf{2 0 0 4}$ guideline?}

No new serious AEs have been identified.

\section{Recommendations for future research}

Head-to-head trials are lacking on newer AEDs in patients with TR focal epilepsy and TR GE. In studies of new-onset epilepsy, higher-dose forced titrations led to higher AE rates. Future studies should use doses commonly used in clinical practice and use flexible-dosing regimens. Finally, there is a lack of placebo-controlled and head-to-head trials of newer AEDs in pediatric patients.

\section{Disclaimer}

Clinical practice guidelines, practice advisories, systematic reviews, and other guidance published by the American Academy of Neurology and its affiliates are assessments of current scientific and clinical information provided as an educational service. The information (1) should not be considered inclusive of all proper treatments, methods of care, or as a statement of the standard of care; (2) is not continually updated and may not reflect the most recent evidence (new evidence may emerge between the time information is developed and when it is published or read); (3) addresses only the question(s) specifically identified; (4) does not mandate any particular course of medical care; and (5) is not intended to substitute for the independent professional judgment of the treating provider, as the information does not account for individual variation among patients. In all cases, the selected course of action should be considered by the treating provider in the context of treating the individual patient. Use of the information is voluntary. AAN provides this information on an as is basis, and makes no warranty, expressed or implied, regarding the information. AAN specifically disclaims any warranties of merchantability or fitness for a particular use or purpose. AAN assumes no responsibility for any injury or damage to persons or property arising out of or related to any use of this information or for any errors or omissions.

\section{Conflict of interest}

The American Academy of Neurology (AAN) and the American Epilepsy Society (AES) are committed to producing independent, critical, and truthful clinical practice guidelines (CPGs). Significant efforts are made to minimize the potential for conflicts of interest to influence the recommendations of this CPG. To the extent possible, the AAN and AES keep separate those who have a financial stake in the success or failure of the products appraised in the CPGs and the developers of the guidelines. Conflict of interest forms were obtained from all authors and reviewed by an oversight committee prior to project initiation. The AAN and AES limit the participation of authors with substantial conflicts of interest. The AAN and AES forbid commercial participation in, or funding of, guideline projects. Drafts of the guideline have been reviewed by at least 3 AAN committees, 3 AES committees, a network of neurologists, Neurology peer reviewers, and representatives from related fields. The AAN Guideline Author Conflict of Interest Policy can be viewed at aan.com. For complete information on this process, access the 2004 AAN process manual. ${ }^{3}$ 


\section{Author contributions}

Andres M. Kanner: study concept and design, acquisition of data, analysis or interpretation of data, drafting/revising the manuscript, critical revision of the manuscript for important intellectual content, study supervision. Eric Ashman: study concept and design, acquisition of data, analysis or interpretation of data, drafting/revising the manuscript, critical revision of the manuscript for important intellectual content, study supervision. David Gloss: acquisition of data, analysis or interpretation of data, drafting/revising the manuscript, critical revision of the manuscript for important intellectual content, study supervision. Cynthia Harden: analysis or interpretation of data, drafting/revising the manuscript, critical revision of the manuscript for important intellectual content, study supervision. Blaise Bourgeois: study concept and design, acquisition of data, analysis or interpretation of data. Jocelyn Bautista: study concept and design, acquisition of data, analysis or interpretation of data. Bassell Abou-Khalil: study concept and design, acquisition of data, analysis or interpretation of data. Evren Burakgazi-Dalkilic: study concept and design, acquisition of data, analysis or interpretation of data. Esmeralda Llanas Park: study concept and design, acquisition of data, analysis or interpretation of data. John Stern: study concept and design, acquisition of data, analysis or interpretation of data. Deborah Hirtz: study concept and design, acquisition of data, analysis or interpretation of data. Marc Nespeca: study concept and design, acquisition of data, analysis or interpretation of data. Barry Gidal: study concept and design, acquisition of data, analysis or interpretation of data. Edward Faught: study concept and design, acquisition of data, analysis or interpretation of data. Jacqueline French: study concept and design, analysis or interpretation of data, drafting/revising the manuscript, critical revision of the manuscript for important intellectual content, study supervision.

\section{Study funding}

This guideline was developed with financial support from the American Academy of Neurology (AAN). Authors who serve as AAN subcommittee members or methodologists (E.A., D.G., C.H., and J.F.) were reimbursed by the AAN for expenses related to travel to subcommittee meetings where drafts of manuscripts were reviewed.

\section{Disclosure}

A. Kanner has served on a scientific advisory board for UCB but the honorarium was transferred to the Department of Neurology at the University of Miami, Miller School of Medicine; receives royalties from Psychiatric Aspects of Epilepsy, Treatment of Depression in Neurologic Disorders, and Psychiatric Controversies in Epilepsy; and received honoraria from Medscape and as a consultant for Neuropace. E. Ashman receives funding from the American Academy of Neurology (AAN) for travel; has served as associate editor, level of evidence, for Neurology $y^{\circledR}$ has performed imaging studies that include MRI, electrophysiology, and EEG in patients who are comatose; and has provided medical reviews and consultations for lawsuits and medical claims as part of his role in the US Air Force. D. Gloss serves as an evidence-based medicine consultant for the AAN. C. Harden receives royalties from UpToDate and Wiley; serves on the speakers' bureau for UBC; and has received research support from the National Institute of Neurologic Disorders and Stroke (NINDS) of the NIH and the Epilepsy Therapy Project. B. Bourgeois serves on the data and safety monitoring board for a clinical trial conducted by Pfizer Pharmaceuticals, for which he receives honoraria; and receives royalties for The Epilepsy Prescriber's Guide to Antiepileptic Drugs. J. Bautista serves on the National Quality Forum Neurology Steering Committee and the Neurology Endorsement Maintenance Committee and has received research funding from the NIH and NINDS. B. Abou-Khalil has served on but declined honoraria from scientific advisory boards for Sunovion and GlaxoSmithKline; served on the editorial board for Epilepsy Research and Clinical Neurophysiology; and received royalties for Atlas of EEG \& Seizure Semiology. His institution received research support from UCB, GlaxoSmithKline, Valeant, Sunovion, UpsherSmith, Pfizer, Cyberonics, and SK Life Science, from the NIH for the Epilepsy Phenome/Genome Project, and from the Human Epilepsy Project. E. Burakgazi-Dalkilic serves on a speakers' bureau for Eisai Pharmaceuticals. E. Llanas Park reports no disclosures relevant to the manuscript. J. Stern serves on the scientific advisory board for Sunovion and Lundbeck; serves as an editor for MedLink Neurology; receives royalties for Atlas of EEG Patterns and Atlas of Video-EEG Monitoring; receives honoraria from and serves on the speakers' bureaus of UCB, Lundbeck, Eisai, Cyberonics, and Sunovion; and performs clinical practice in epilepsy (50\% of his time). D. Hirtz reports no disclosures relevant to the manuscript. M. Nespeca serves on the Scientific Advisory Committee of the Angelman Syndrome Foundation; is a coinvestigator for a US Food and Drug Administration-funded trial on levetiracetam vs phenobarbital in neonatal seizures and for industry-sponsored trials on everolimus (Novartis) for epilepsy in persons with tuberous sclerosis and on fenfluramine (Zogenix) in Dravet syndrome. B. Gidal serves on science advisory boards and speakers bureaus for UCB, Eisai, and Sunovion, for which he receives honoraria; performs clinical practice in epilepsy ( $20 \%$ of his time); and has provided expert testimony, prepared an affidavit, and acted as a witness in the legal proceeding of Activis v Depomed. E. Faught serves on the scientific advisory boards of Eisai, Lundbeck, SK Life Science, Supernus, Sunovion, and UCB; has received research support from Brain Sentinel, UCB, the Centers for Disease Control and Prevention, University of Alabama at Birmingham, and the Epilepsy Consortium; and has acted as a witness in legal proceedings for Rushton Stakley. J. French serves on the scientific advisory board of Anavex Life Science Corp.; receives travel funding from Upsher-Smith, Marinus Pharmaceuticals, Pfizer, SK Life Science, Biotie, GW Pharmaceuticals, UCB, and Takeda; serves as an editor for Epilepsia; and receives research support from Acorda, Biotie, Eisai, GlaxoSmithKline, Impax, Johnson \& Johnson, Marinus Pharmaceuticals, Novartis, Pfizer, 
Sunovion, SK Life Science, Supernus, and the NINDS of the $\mathrm{NIH}$. Go to Neurology.org/N for full disclosures.

Received March 2, 2017. Accepted in final form March 29, 2018.

\section{References}

1. French J, Smith M, Faught E, Brown L. Practice advisory: the use of felbamate in the treatment of patients with intractable epilepsy: report of the Quality Standards Subcommittee of the American Academy of Neurology and the American Epilepsy Society. Neurology 1999;52:1540-1545.

2. French JA, Kanner AM, Bautista J, et al. Efficacy and tolerability of the new antiepileptic drugs II: treatment of refractory epilepsy: report of the Therapeutics and Technology Assessment Subcommittee and Quality Standards Subcommittee of the American Academy of Neurology and the American Epilepsy Society. Neurology 2004;62:1261-1273.

3. American Academy of Neurology. Clinical Practice Guidelines Process Manual, 2004 ed. St. Paul: The American Academy of Neurology; 2004.

4. French JA, Kugler AR, Robbins JL, Knapp LE, Garofalo EA. Dose-response trial of pregabalin adjunctive therapy in patients with partial seizures. Neurology 2003;60: 1631-1637.

5. Arroyo S, Anhut H, Kugler AR, et al; Pregabalin 1008-011 International Study Group. Pregabalin add-on treatment: a randomized, double-blind, placebo-controlled, doseresponse study in adults with partial seizures. Epilepsia 2004;45:20-27.

6. Beydoun A, Uthman BM, Kugler AR, Greiner MJ, Knapp LE, Garofalo EA; Pregabalin 1008-009 Study Group. Safety and efficacy of two pregabalin regimens for add-on treatment of partial epilepsy. Neurology 2005;64:475-480.

7. Elger CE, Brodie MJ, Anhut H, Lee CM, Barrett JA. Pregabalin add-on treatment in patients with partial seizures: a novel evaluation of flexible-dose and fixed-dose treatment in a double-blind, placebo-controlled study. Epilepsia 2005;46:1926-1936.

8. French J, Brandt C, Friedman D, et al. Adjunctive use of controlled-release pregabalin in adults with treatment-resistant partial seizures: a double-blind, randomized, placebo-controlled trial. Epilepsia 2014;55:1220-1228.

9. Halász P, Kälviäinen R, Mazurkiewicz-Beldzińska M, et al; SP755 Study Group. Adjunctive lacosamide for partial-onset seizures: efficacy and safety results from a randomized controlled trial. Epilepsia 2009;50:443-453.

10. Chung S, Sperling MR, Biton V, et al; SP754 Study Group. Lacosamide as adjunctive therapy for partial-onset seizures: a randomized controlled trial. Epilepsia 2010;5:958-967.

11. Ben-Menachem E, Biton V, Jatuzis D, Abou-Khalil B, Doty P, Rudd GD. Efficacy and safety of oral lacosamide as adjunctive therapy in adults with partial-onset seizures. Epilepsia 2007;48:1308-1317.

12. Krauss G, Ben-Menachem E, Mameniskiene R, et al; SP757 Study Group. Intravenous lacosamide as short-term replacement for oral lacosamide in partial-onset seizures. Epilepsia 2010;51:951-957.

13. Sake JK, Hebert D, Isojärvi J, et al. A pooled analysis of lacosamide clinical trial data grouped by mechanism of action of concomitant antiepileptic drugs. CNS Drugs 2010;24:1055-1068.

14. Brodie MJ, Rosenfeld WE, Vazquez B, et al. Rufinamide for the adjunctive treatment of partial seizures in adults and adolescents: a randomized placebo-controlled trial. Epilepsia 2009;50:1899-1909.

15. Elger CE, Stefan H, Mann A, Narurkar M, Sun Y, Perdomo CA. 24-week multicenter, randomized, double-blind, parallel-group, dose-ranging study of rufinamide in adults and adolescents with inadequately controlled partial seizures. Epilepsy Res 2010;88: $255-263$.

16. Biton V, Krauss G, Vasquez-Santana B, et al. A randomized, double-blind, placebocontrolled, parallel-group study of rufinamide as adjunctive therapy for refractory partial-onset seizures. Epilepsia 2011;52:234-242.

17. Brodie MJ, Lerche H, Gil-Nagel A, et al; RESTORE 2 Study Group. Efficacy and safety of adjunctive ezogabine (retigabine) in refractory partial epilepsy. Neurology 2010;75:1817-1824.

18. Porter RJ, Partiot A, Sachdeo R, Nohria V, Alves WM; 205 Study Group. Randomized, multicenter, dose-ranging trial of retigabine for partial-onset seizures. Neurology 2007;68:1197-1204.

19. French JA, Abou-Khalil BW, Leroy RF, et al; RESTORE 1/Study 301 Investigators. Randomized, double-blind, placebo-controlled trial of ezogabine (retigabine) in partial epilepsy. Neurology 2011;76:1555-1563.
20. Biton V, Gil-Nagel A, Brodie MJ, Derossett SE, Nohria V. Safety and tolerability of different titration rates of retigabine (ezogabine) in patients with partial-onset seizures. Epilepsy Res 2013;107:138-145.

21. French JA, Mosier M, Walker S, Sommerville K, Sussman N. A double-blind, placebocontrolled study of vigabatrin three $\mathrm{g} /$ day in patients with uncontrolled complex partial seizures: Vigabatrin Protocol 024 Investigative Cohort. Neurology 1996;46: 54-61.

22. Dean C, Mosier M, Penry K. Dose-response study of vigabatrin as add-on therapy in patients with uncontrolled complex partial seizures. Epilepsia 1999;40:74-82.

23. Maguire MJ, Hemming K, Wild JM, Hutton JL, Marson AG. Prevalence of visual field loss following exposure to vigabatrin therapy: a systematic review. Epilepsia 2010;51: 2423-2431.

24. Koeppen D, Baruzzi A, Capozza M, et al. Clobazam in therapy-resistant patients with partial epilepsy: a double-blind placebo-controlled crossover study. Epilepsia 1987; 28:495-506.

25. Schmidt D, Rohde M, Wolf P, Roeder-Wanner U. Clobazam for refractory focal epilepsy: a controlled trial. Arch Neurol 1986;43:824-826.

26. Allen JW, Oxley J, Robertson MM, Trimble MR, Richens A, Jawad SS. Clobazam as adjunctive treatment in refractory epilepsy. Br Med J 1983;286:1246-1247.

27. French JA, Krauss GL, Steinhoff BJ, et al. Evaluation of adjunctive perampanel in patients with refractory partial-onset seizures: results of randomized global phase III study 305. Epilepsia 2013;54:117-125.

28. French JA, Krauss GL, Biton V, et al. Adjunctive perampanel for refractory partial-onset seizures: randomized phase III study 304. Neurology 2012;79: 589-596.

29. Krauss GL, Serratosa JM, Villanueva V, et al. Randomized phase III study 306: adjunctive perampanel for refractory partial-onset seizures. Neurology 2012;78: $1408-1415$.

30. Elger C, Halász P, Maia J, Almeida L, Soares-da-Silva P; BIA-2093-301 Investigators Study Group. Efficacy and safety of eslicarbazepine acetate as adjunctive treatment in adults with refractory partial-onset seizures: a randomized, doubleblind, placebo-controlled, parallel-group phase III study. Epilepsia 2009;50: 454-463.

31. Gil-Nagel A, Lopes-Lima J, Almeida L, Maia J, Soares-da-Silva P; BIA-2093-303 Investigators Study Group. Efficacy and safety of 800 and $1200 \mathrm{mg}$ eslicarbazepine acetate as adjunctive treatment in adults with refractory partial-onset seizures. Acta Neurol Scand 2009;120:281-287.

32. Ben-Menachem E, Gabbai AA, Hufnagel A, Maia J, Almeida L, Soares-da-Silva P. Eslicarbazepine acetate as adjunctive therapy in adult patients with partial epilepsy. Epilepsy Res 2010;89:278-285.

33. French JA, Baroldi P, Brittain ST, Johnson JK; PROSPER Investigators Study Group. Efficacy and safety of extended-release oxcarbazepine (Oxtellar XR ${ }^{T M}$ ) as adjunctive therapy in patients with refractory partial-onset seizures: a randomized controlled trial. Acta Neurol Scand 2014;129:143-153.

34. Chung SS, Fakhoury TA, Hogan RE, et al; PREVAIL Study Group. Once-daily USL255 as adjunctive treatment of partial-onset seizures: randomized phase III study. Epilepsia 2014;55:1077-1087.

35. Chung S, Ceja H, Gawłowicz J, et al. Levetiracetam extended release conversion to monotherapy for the treatment of patients with partial-onset seizures: a doubleblind, randomised, multicentre, historical control study. Epilepsy Res 2012;101: 92-102.

36. French J, Kwan P, Fakhoury T, et al. Pregabalin monotherapy in patients with partialonset seizures: a historical-controlled trial. Neurology 2014;82:590-597.

37. Wechsler RT, Li G, French J, et al; ALEX-MT Study Group. Conversion to lacosamide monotherapy in the treatment of focal epilepsy: results from a historicalcontrolled, multicenter, double-blind study. Epilepsia 2014;55:1088-1098.

38. Sperling MR, Harvey J, Grinell T, Cheng H, Blum D. Efficacy and safety of conversion to monotherapy with eslicarbazepine acetate in adults with uncontrolled partial-onset seizures: a randomized historical-control phase III study based in North America. Epilepsia 2015;56:546-555.

39. Jacobson MP, Pazdera L, Bhatia P, Grinnell T, Cheng H, Blum D. Efficacy and safety of conversion to monotherapy with eslicarbazepine acetate in adults with uncontrolled partial-onset seizures: a historical-control phase III study. BMC Neurol $2015 ; 15: 46$

40. Biton V, Sackellares JC, Vuong A, Hammer AE, Barrett PS, Messenheimer JA Double-blind, placebo-controlled study of lamotrigine in primary generalized tonicclonic seizures. Neurology 2005;65:1737-1743. 


\section{Neurology}

Practice guideline update summary: Efficacy and tolerability of the new antiepileptic drugs II: Treatment-resistant epilepsy: Report of the Guideline Development, Dissemination, and Implementation Subcommittee of the American Academy of

Neurology and the American Epilepsy Society

Andres M. Kanner, Eric Ashman, David Gloss, et al.

Neurology 2018;91;82-90 Published Online before print June 13, 2018

DOI 10.1212/WNL.0000000000005756

This information is current as of June 13, 2018

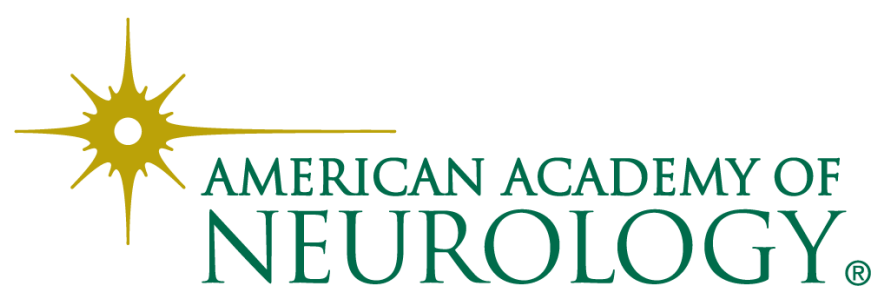




\section{Updated Information \& Services}

\section{Supplementary Material}

References

Citations

Subspecialty Collections

Errata

Permissions \& Licensing

Reprints including high resolution figures, can be found at:

http://n.neurology.org/content/91/2/82.full

Supplementary material can be found at: http://n.neurology.org/content/suppl/2019/01/01/WNL.0000000000005 756.DC1

This article cites 39 articles, 13 of which you can access for free at: http://n.neurology.org/content/91/2/82.full\#ref-list-1

This article has been cited by 1 HighWire-hosted articles: http://n.neurology.org/content/91/2/82.full\#\#otherarticles

This article, along with others on similar topics, appears in the following collection(s):

All Epilepsy/Seizures

http://n.neurology.org/cgi/collection/all_epilepsy_seizures Antiepileptic drugs

http://n.neurology.org/cgi/collection/antiepileptic_drugs

An erratum has been published regarding this article. Please see next page or:

/content/91/24/1117.3.full.pdf

Information about reproducing this article in parts (figures,tables) or in its entirety can be found online at:

http://www.neurology.org/about/about_the_journal\#permissions

Information about ordering reprints can be found online:

http://n.neurology.org/subscribers/advertise

Neurology ${ }^{\circledR}$ is the official journal of the American Academy of Neurology. Published continuously since 1951 , it is now a weekly with 48 issues per year. Copyright @ 2018 American Academy of Neurology. All rights reserved. Print ISSN: 0028-3878. Online ISSN: 1526-632X.

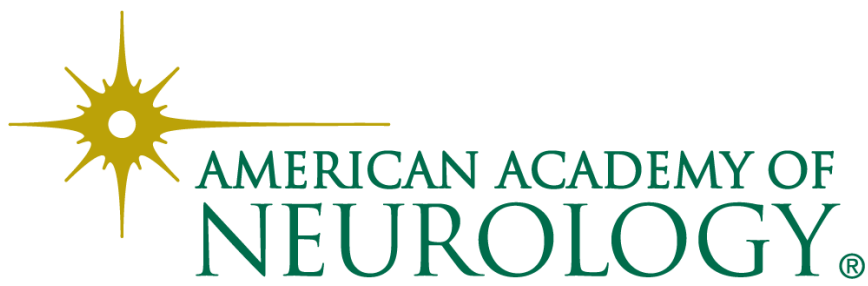




\section{Generalized polyspike train}

An EEG biomarker of drug-resistant idiopathic generalized epilepsy

Neurology ${ }^{\circledR}$ 2018;91:1117. doi:10.1212/WNL.0000000000006797

In the article "Generalized polyspike train: An EEG biomarker of drug-resistant idiopathic generalized epilepsy” by Sun et al., ${ }^{1}$ one author's name should read as Kee Meng Tan. The authors regret the errors.

\section{Reference}

1. Sun Y, Seneviratne U, Perucca P, et al. Generalized polyspike train: an EEG biomarker of drug-resistant idiopathic generalized epilepsy. Neurology 2018;91:e1822-e1830.

\section{Novel biomarker signatures for idiopathic REM sleep behavior disorder}

A proteomic and system biology approach

Neurology ${ }^{\circledR}$ 2018;91:1117. doi:10.1212/WNL.0000000000006791

In the article "Novel biomarker signatures for idiopathic REM sleep behavior disorder: A proteomic and system biology approach" by Mondello et al., ${ }^{1}$ the institution for Dr. Giuseppe Plazzi, Dr. Elena Antelmi, and Dr. Monica Moresco should read as the "University of Bologna and IRCCS Istituto delle Scienze Neurologiche di Bologna, Bologna, Italy.” The authors regret the error.

\section{Reference}

1. Mondello S, Kobeissy F, Mechref Y, et al. Novel biomarker signatures for idiopathic REM sleep behavior disorder: a proteomic and system biology approach. Neurology 2018;91:e1710-e1715.

\section{Practice guideline update summary: Efficacy and tolerability of the new antiepileptic drugs II: Treatment-resistant epilepsy}

Report of the Guideline Development, Dissemination, and Implementation Subcommittee of the American Academy of Neurology and the American Epilepsy Society

Neurology ${ }^{\circledR}$ 2018;91:1117. doi:10.1212/WNL.0000000000006636

In the article "Practice guideline update summary: Efficacy and tolerability of the new antiepileptic drugs II: Treatment-resistant epilepsy" by Kanner et al., ${ }^{1}$ there is an error in the abstract, which should have read "2004 criteria were used to systematically review literature" rather than "...systemically review..." as originally published. The authors regret the error.

\section{Reference}

1. Kanner AM, Ashman E, Glass D, et al. Practice guideline update summary: efficacy and tolerability of the new antiepileptic drugs II: treatment-resistant epilepsy. Neurology 2018;91:82-90. 